\title{
Primary hepatic extranodal marginal zone lymphoma of mucosa-associated lymphoid tissue
}

\author{
Soyeon Choi ${ }^{1}$, Ji Hye Kim ${ }^{1}$, Kyungbin Kim ${ }^{1}$, Misung $\mathrm{Kim}^{1}$, Hye Jeong Choi ${ }^{1,2}$, \\ Young Min Kim ${ }^{1,2}$, Jae Hee Suh ${ }^{1,2}$, Min Jung Seo ${ }^{2,3}$, Hee Jeong Cha ${ }^{1,2}$ \\ 'Department of Pathology, Ulsan University Hospital, Ulsan; university of Ulsan College of Medicine, Ulsan; \\ ${ }^{3}$ Department of Nuclear Medicine, Ulsan University Hospital, Ulsan, Korea
}

\begin{abstract}
Extranodal marginal zone lymphoma of mucosa-associated lymphoid tissue (MALT lymphoma), is one of the specific type of low-grade B-cell lymphoma not infrequently found worldwide. It typically involves mucosal sites such as stomach and conjunctiva; however, primary hepatic MALT Iymphoma has been extremely rarely reported. We describe a case of hepatic MALT lymphoma in a 70-year-old male patient who underwent left hepatectomy due to the incidentally detected liver masses at a medical checkup. The resected specimen revealed multinodular masses consisting of small-to-intermediate-sized lymphoid cells with serpentine pattern and focal lymphoepithelial lesions. The tumor cells were diffusely positive for CD20 and Bcl-2 but negative for CD3, CD10, CD5, CD23, CD43, and cyclinD1. The Ki-67 labeling index was $10 \%$ and immunoglobulin heavy chain gene rearrangement study confirmed monoclonal proliferation. In this paper, we discuss several unique clinicopathologic characteristics which will be helpful to the differential diagnosis of hepatic MALT lymphoma.
\end{abstract}

Key Words: Lymphoma, B-cell, marginal zone; Mucosa-associated lymphoid tissue; Liver

Received: December 27, 2019 Revised: March 10, 2020 Accepted: March 17, 2020

Corresponding Author: Hee Jeong Cha, MD, Department of Pathology, Ulsan University Hospital, University of Ulsan College of Medicine, 877 Bangeojinsunhwan-doro, Dong-gu, Ulsan 44033, Korea

Tel: +82-52-250-7261, Fax: +82-52-252-3024, E-mail: heej0124@uuh.ulsan.kr

Extranodal marginal zone lymphoma of mucosa-associated lymphoid tissue (MALT) is one of the specific type of low-grade B-cell lymphoma not infrequently found worldwide. MALT lymphoma represents $7 \%-8 \%$ of all non-Hodgkin's lymphomas in Western countries [1]. In Korea, MALT lymphomas represent $19.0 \%$ of non-Hodgkin lymphomas and over half $(59.8 \%)$ occur in the stomach. Other sites of occurrence include the lung, salivary gland, ocular adnexa, skin, and thyroid [2]. However, lymphoma in the liver as the primary site is very rare. Primary hepatic lymphoma (PHL) comprises $0.016 \%$ of nonHodgkin's lymphoma [3] and MALT lymphoma comprises $2 \%-4 \%$ of PHL [4]. Since it is a rare disease with limited literature, there is no consensus on treatment modalities $[5,6]$. Here, we report a case of primary hepatic MALT lymphoma.

\section{CASE REPORT}

A 70-year-old male patient was referred for liver masses on ultrasonography from a medical checkup at another hospital. He had a history of intracerebral hemorrhage, and coronary stent insertion due to myocardial infarction. A physical examination showed no abnormalities. The laboratory test results were within normal limits. The level of aspartate transaminase was $27 \mathrm{IU} / \mathrm{L}$, alanine transaminase was $24 \mathrm{IU} / \mathrm{L}$, total bilirubin was $0.9 \mathrm{mg} / \mathrm{dL}$, alkaline phosphatase was $96 \mathrm{IU} / \mathrm{L}$, and $\gamma$ glutamyl transferase was $34 \mathrm{IU} / \mathrm{L}$. The patient was seronegative for hepatitis B and C and tumor markers ( $\alpha$-fetoprotein and protein induced by vitamin $\mathrm{K}$ antagonist II) were within normal limits. He was also seronegative for human immunodeficiency virus and was negative for antinuclear antibody. The abdomen ultrasonography showed mild fatty liver. Esophagogastroduodenoscopy showed atrophic gastritis and no other MALT lesion 


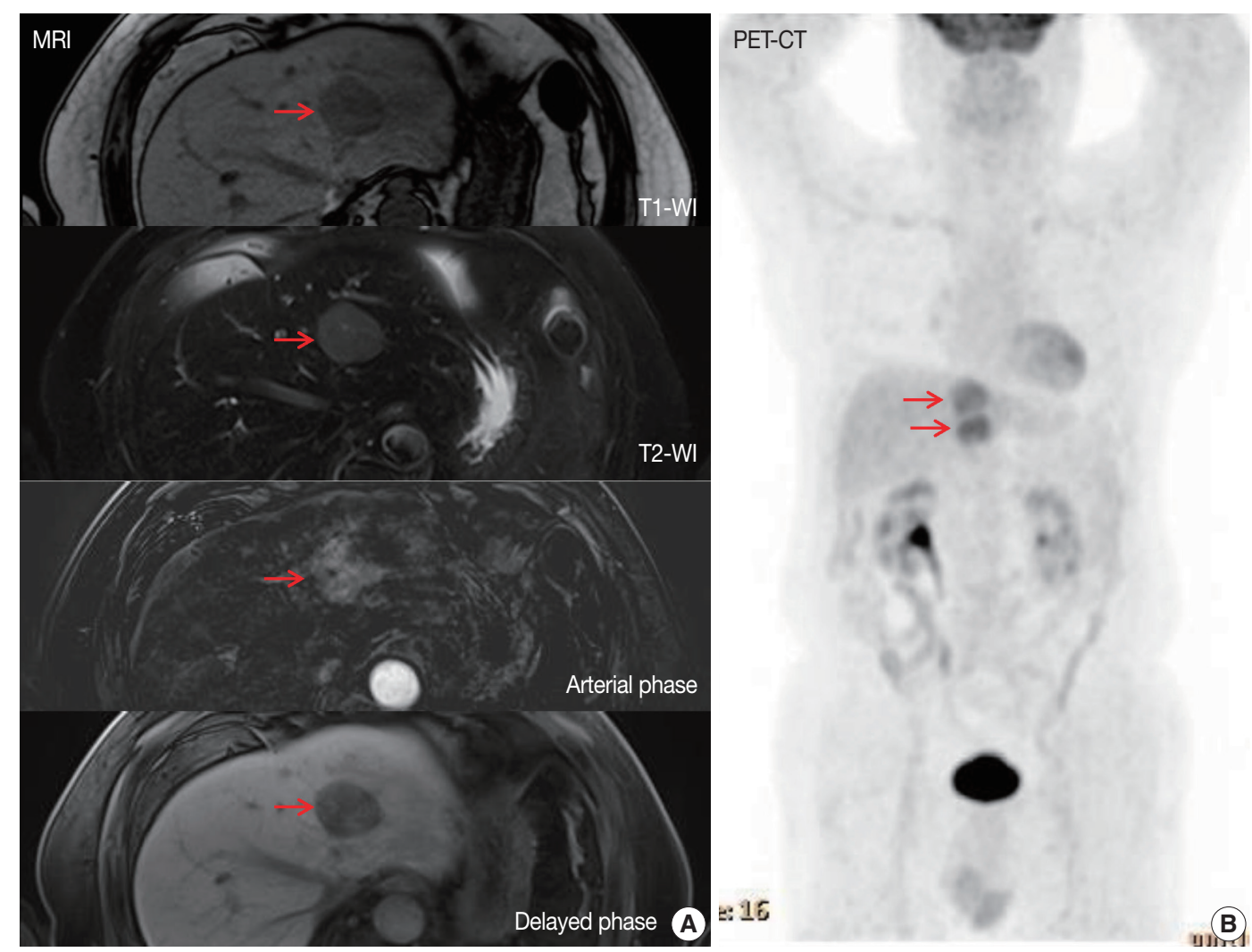

Fig. 1. (A) The magnetic resonance imaging shows a hypointense in $\mathrm{T} 1$, and $\mathrm{T} 2$, and arterial enhancing lesion in left lateral segment (arrows). (B) The positron emission tomography/computed tomography shows two hypermetabolic masses in left lateral segment (maximal standardized uptake value, 4.4). T1-WI, T1 weighted image; T2-WI, T2 weighted image.

was present. Further imaging studies including computed tomography (CT), magnetic resonance imaging (MRI), and ${ }^{18} \mathrm{~F}$ fluorodeoxyglucose (FDG)-positron emission tomography (PET)/CT were performed. The MRI revealed two arterial enhancing masses measuring $3.6 \mathrm{~cm}$ and $3.3 \mathrm{~cm}$ in the left lateral segment of the liver, suggesting hepatocellular carcinoma (HCC) (Fig. 1A). The PET/CT revealed the two masses in the left lateral segment of the liver to be hypermetabolic (maximum standardized uptake value of 4.4) (Fig. 1B). No other lymphadenopathy was present. He underwent left hepatectomy.

The liver specimen showed two masses measuring $4.8 \times 4.2 \times$ $3.3 \mathrm{~cm}$ and $4.8 \times 3.8 \times 2.3 \mathrm{~cm}$ that were well-demarcated and grayish tan in color in segment 2 (Fig. 2A). On low-power magnification, nodular and serpentine infiltration of lymphocytes was seen (Fig. 2B). On high-power magnification, small-to-intermediate-sized lymphoid cells were present (Fig. 2C). Lymphoepithelial lesions were present in the bile ducts (Fig. 2D), which were highlighted by positive immunoreactivity for cytokeratin 7 by immunohistochemistry (IHC) (Fig. 2E). In other IHC studies, $\mathrm{CD} 20$ and Bcl-2 were diffusely and strongly positive, and the tumor cells were negative for $\mathrm{CD} 3, \mathrm{CD} 10, \mathrm{CD} 5, \mathrm{CD} 23, \mathrm{CD} 43$, and cyclinD1 (Fig. 3A-C). The Ki-67 index was about 10\%. Immunoglobulin heavy chain $(\mathrm{IgH})$ gene rearrangement study revealed monoclonality of the lymphoid lesion, and all these results were compatible with a diagnosis of MALT lymphoma. The background liver outside the nodules showed portal-to-periportal lymphocytic infiltration (Fig. 3D), however, there was no evidence of autoimmune hepatitis, or primary biliary cirrhosis, or non-alcoholic steatohepatitis. Systemic studies including bone marrow biopsy showed no additional lesions. He was diagnosed with Ann Arbor stage IIE and close follow-up without additional therapy was recommended. After 8 months from the surgery, the patient showed no recurrent disease in the CT scan.

\section{DISCUSSION}

Although the incidence of primary hepatic MALT lymphoma is extremely rare, some unique clinical characteristics were reported in the literatures (Table 1) [6-15]. Most of primary hepatic MALT lymphoma cases occurred in elderly people and were presented with incidentally detected liver masses without specific symptoms $[6,7]$. These features were consistent with 
the present case.

Chronic antigenic stimulation such as longstanding inflammation or infection has been suggested as an important etiologic factor of MALT lymphoma. Helicobacter pylori has been proved to be the cause of gastric MALT lymphoma and the suggested infectious agents for other sites are Borrelia burdorferi for skin, Chlamydophila psittaci for ocular adnexa, Campylobacter jejuni for small intestine, and Achromobacter xylosoxidans for lung. As
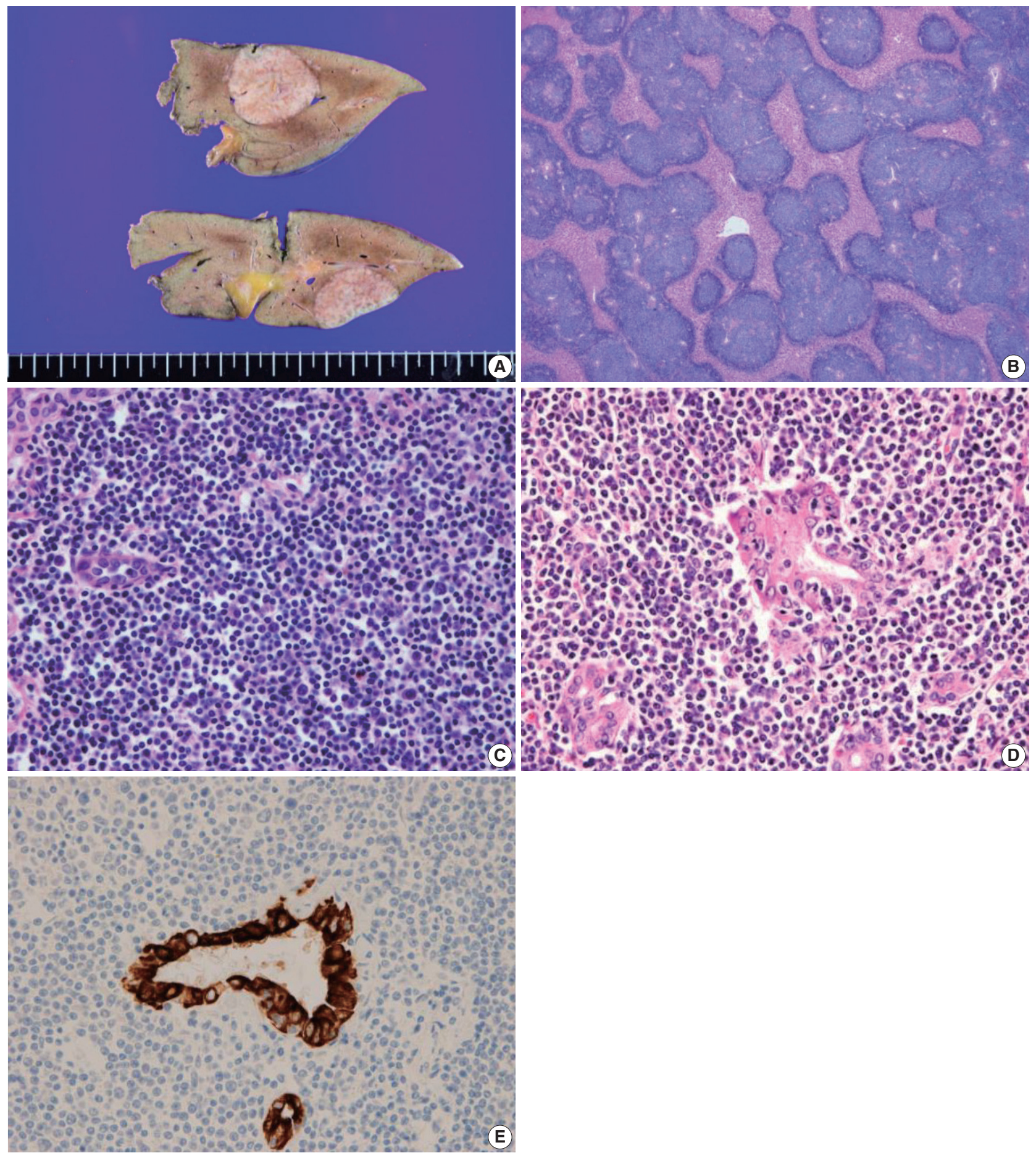

Fig. 2. (A) Gross image of the liver shows well-demarcated and grayish tan masses. (B) Low power view of the lesion demonstrates serpentine infiltrations of lymphoid cells. (C) High power view of the lesion demonstrates small-to-intermediated-size lymphoid cell infiltration. (D, E) Lymphoepithelial lesion is present, which is revealed by cytokeratin 7 immunohistochemical stain. 

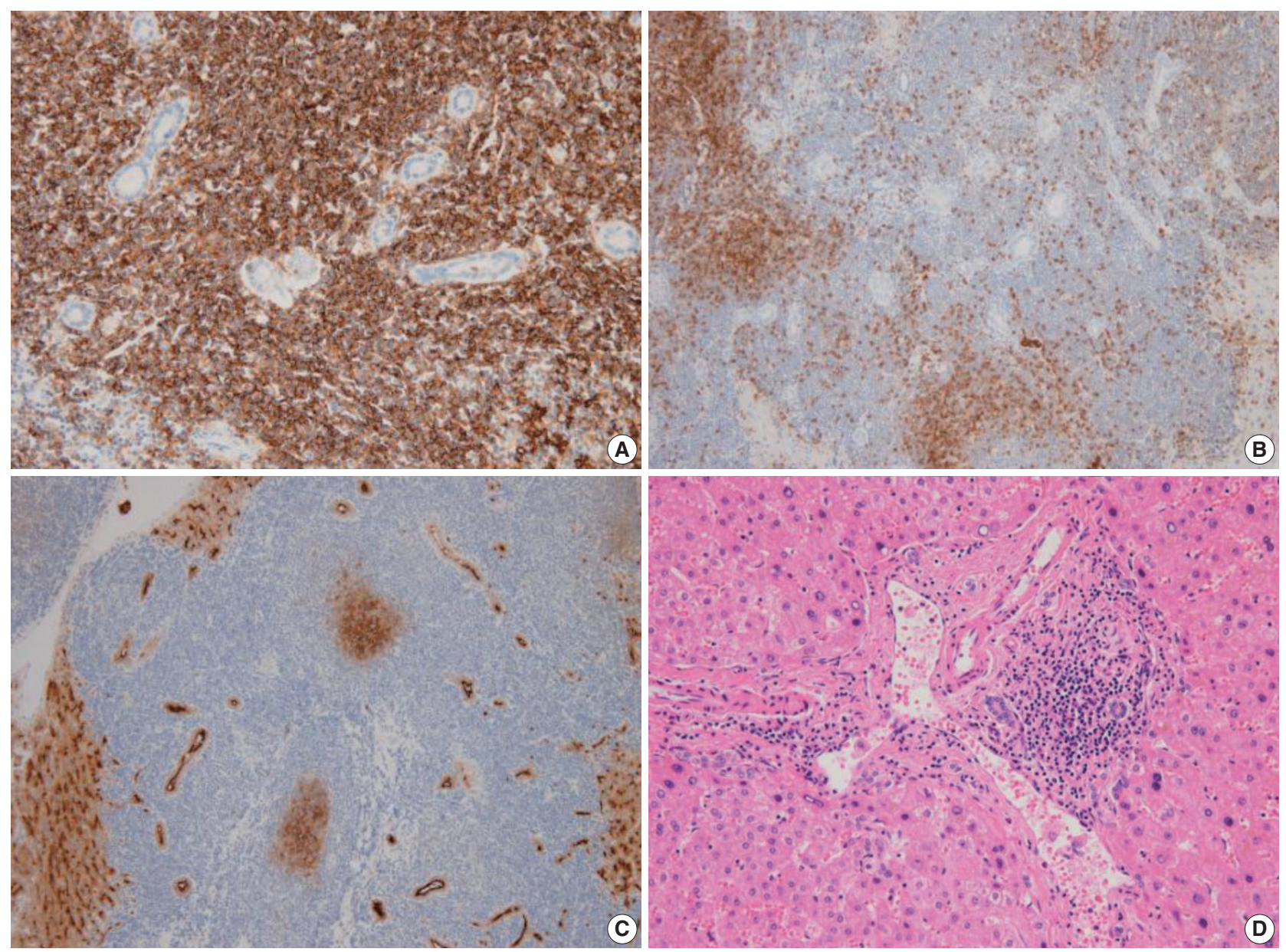

Fig. 3. The lymphoid cells are positive for CD20 (A), and negative for CD3 (B) and CD10 (C). (D) The non-neoplastic liver shows portal to periportal lymphocytic infiltration.

for hepatic MALT lymphoma, hepatitis $C$ viral infection, autoimmune diseases such as Sjogren's disease or Hashimoto's thyroiditis have been reported to have increased the risk of MALT lymphoma $[16,17]$. Another study proposed that $45 \%$ of patients with MALT lymphoma had no concomitant liver diseases [6]. Our patient had no suggested predisposing conditions listed above. The pathogenesis of hepatic MALT lymphoma is still unclear and should be explored in a large-scale study.

In this case, the patient was initially misdiagnosed with HCC by $\mathrm{CT}$ and MRI studies. Betianu et al. [8] states that there are no characteristic radiological findings of PHL. After contrast administration, more than $50 \%$ of PHLs showed no enhancement, $30 \%$ showed patchy enhancement and $15 \%$ showed a ring enhancement. On MRI, PHL is hypo- or isointense on T1 and hyperintense on T2 [8]. Thus, when suspected malignant liver masses are seen in imaging studies without elevation of tumor markers, lymphoma should be a differential diagnosis and liver biopsy could be an option. Several articles focus on ${ }^{18} \mathrm{~F}-\mathrm{FDG}$ $\mathrm{PET} / \mathrm{CT}$ as a diagnostic modality as for other lymphomas. Bao et al. [9] suggest that ${ }^{18} \mathrm{~F}-\mathrm{FDG}$ PET/CT is particularly helpful in distinguishing the initial stages of MALT lymphoma, although pathological evidence is needed for definitive diagnosis. It can assist in staging, evaluating treatment responses, and monitoring relapse and recurrence [9]. Our patient had a slightly hypermetabolic mass, considering its indolent nature. The standardized uptake value of primary hepatic MALT lymphoma remains to be validated with more evidence.

Microscopically, in low-power magnification, nodular and serpentine infiltrations of lymphoid cells from the portal area were present. MALT lymphomas are known to predominantly involve the portal fields of the liver, and lymphoepithelial lesions of the bile ducts are known to be typical accompanying findings [18]. The differential diagnoses are HCC, cholangiocellular carcinoma, low-grade B-cell lymphoma including follicu- 
Table 1. Reported cases of primary hepatic MALT Iymphoma

\begin{tabular}{|c|c|c|c|c|c|c|c|c|}
\hline $\begin{array}{l}\text { Case } \\
\text { No. }\end{array}$ & Study & Age $(y r) / S e x$ & HBV & $\mathrm{HCV}$ & Comorbidities & Image finding & Treatment & Outcome \\
\hline 1 & Xie et al. [6] & $73 / \mathrm{M}$ & $(+)$ & $(-)$ & None & $\begin{array}{l}\text { CT: enhanced in arterial phase } \\
\text { MRI: hypointense on } \mathrm{T} 1 \text {, } \\
\text { hyperintense on } \mathrm{T} 2\end{array}$ & Surgery & Alive/6 mo \\
\hline 2 & Nagata et al. [7] & $74 / \mathrm{M}$ & $(-)$ & $(-)$ & Hypertension & $\begin{array}{l}\text { CT: no mass } \\
\text { MRI: enhanced on T1 in arterial } \\
\text { phase, withdrawal in portal venous } \\
\text { and delayed phases }\end{array}$ & Surgery & Alive/2 yr \\
\hline 3 & Betianu et al. [8] & $47 / F$ & $(-)$ & $(-)$ & None & $\begin{array}{l}\text { CT: hypodense mass } \\
\text { MRI: hypointense on T1, } \\
\text { hyperintense on T2 }\end{array}$ & $\begin{array}{l}\text { Surgery and } \\
\text { chemotherapy }\end{array}$ & Alive/9 mo \\
\hline 4 & Bao et al. [9] & $59 / F$ & $(+)$ & $(-)$ & None & $\begin{array}{l}\text { CT: hypodense lesions } \\
\text { PET/CT: increased uptake of SUV }\end{array}$ & Patient refused & ND \\
\hline 5 & Obiorah et al. [10] & $80 / F$ & $(-)$ & $(-)$ & None & CT: bilobed mass & $\begin{array}{l}\text { Surgery, rituximab } \\
\text { and idelalisib }\end{array}$ & $\begin{array}{l}\text { Pulmonary } \\
\text { recur/1 yr, } \\
\text { parotid gland } \\
\text { recur/7 yr }\end{array}$ \\
\hline 6 & Obiorah et al. [10] & $30 / F$ & $(-)$ & $(-)$ & $\begin{array}{l}\text { Autoimmune hepatitis, } \\
\text { Hashimoto's thyroiditis }\end{array}$ & PET/CT: diffuse FDG activity & Rituximab & Alive/3 yr \\
\hline 7 & Bohlok et al. [11] & $68 / M$ & $(-)$ & $(-)$ & $\begin{array}{l}\text { Alcoholic cirrhosis, } \\
\text { hemochromatosis }\end{array}$ & $\begin{array}{l}\text { MRI: enhanced in arterial phase and } \\
\text { washout in portal phase } \\
\text { FDG PET: hypermetabolic tumor }\end{array}$ & Surgery & ND \\
\hline 8 & Khurana et al. [12] & $71 / F$ & $(-)$ & $(-)$ & $\begin{array}{l}\text { Invasive breast cancer, } \\
\text { papillary thyroid carcinoma }\end{array}$ & PET: FDG hypodense lesion & Surgery & ND \\
\hline 9 & Dong et al. [13] & $50 / M$ & $(-)$ & $(-)$ & $\begin{array}{l}\text { Type } 2 \text { diabetes, } \\
\text { hypertension }\end{array}$ & $\begin{array}{l}\text { MRl: hypointense on } \mathrm{T} 1 \text { and } \\
\text { hyperintense on } \mathrm{T} 2 \text {, enhanced in } \\
\text { the arterial phase and portal phase }\end{array}$ & $\begin{array}{l}\text { Surgery and } \\
\text { Rituximab }\end{array}$ & Alive/13 mo \\
\hline 10 & Li et al. [14] & $44 / F$ & $(-)$ & $(+)$ & None & MRl: hyperintense on $\mathrm{T} 1$ and $\mathrm{T} 2$ & Surgery & Alive/27 mo \\
\hline 11 & Haefliger et al. [15] & $69 / \mathrm{M}$ & $(-)$ & $(-)$ & $\begin{array}{l}\text { Non-alcoholic steatohepatitis, } \\
\text { Helicobacter pylori-associated } \\
\text { gastritis }\end{array}$ & $\begin{array}{l}\text { MRI: hyperintense on T2, } \\
\text { washout on portal venous phase }\end{array}$ & $\begin{array}{l}\text { Rituximab and } \\
\text { HP eradication } \\
\text { therapy }\end{array}$ & Alive/6 mo \\
\hline 12 & Our case & 70/M & $(-)$ & $(-)$ & $\begin{array}{l}\text { Intracerebral hemorrhage, } \\
\text { myocardial infarction }\end{array}$ & $\begin{array}{l}\text { MRI: enhanced in arterial phase } \\
\text { PET/CT: hypermetabolic and } \\
\text { isometabolic nodules }\end{array}$ & Surgery & Alive/8 mo \\
\hline
\end{tabular}

MALT, mucosa-associated lymphoid tissue; HBV, hepatitis B virus; $\mathrm{HCV}$, hepatitis C virus; $\mathrm{M}$, male; $\mathrm{CT}$, computed tomography; MRI, magnetic resonance imaging; F, female; PET, positron emission tomography; SUV, standardized uptake value; ND, not detected; FDG, fluorodeoxyglucose; HP, Helicobacter pylori.

lar lymphoma and small lymphocytic lymphoma, hepatosplenic T-cell lymphoma, pseudolymphoma, and IgG4-related liver disease. IHC with CD5, CD10, CD23, CD43, and cyclinD1 is critically important to further classify low-grade B-cell lymphomas. Hepatic pseudolymphoma is another rare lesion often associated with inflammatory or autoimmune diseases and shows features similar to malignant lesions in imaging. Its histologic findings resemble low-grade lymphoma, particularly extranodal marginal zone lymphoma [19]. It can be distinguished from extranodal marginal zone lymphoma by histology, and IHC studies showing reactive patterns and polyclonality in an $\mathrm{IgH}$ gene rearrangement study. The diagnostic features of IgG4-related disease include elevated serum IgG4 concentrations, and histologic features include dense lymphoplasmacytic inflammatory infiltrate with increased numbers of $\operatorname{IgG} 4^{+}$plasma cells, often increased eosinophils, a storiform pattern of fibrosis, and obliter- ative vasculitis [20]. The histologic findings along with results from IHC study and IgH gene rearrangement study seem to be critical in the differential diagnosis.

H.pylori eradication is a well-established treatment for gastric MALT lymphoma. However, there is no consensus on the treatment for MALT lymphoma in other sites. Expectant observation, surgery, radiotherapy, chemotherapy, and immunotherapy are generally performed, considering site, disease stage, and performance status. For localized diseases, radiation therapy is often a preferred option and surgery can be considered. For advanced stages, observation with monitoring was often proven to be adequate, but when treatment is required, chemotherapy with rituximab and enrollment in controlled clinical trials is suggested [5]. After discussion, our patient was placed under observation. Tumor recurrence has been reported in the literature, with the lung reported as the most common site [10]. 
Primary hepatic MALT lymphoma is a very rare disease. The clinical features are nonspecific and the image findings variable. Histology, IHC studies and an $\mathrm{IgH}$ gene rearrangement study are of great importance in accurate diagnosis. The disease characteristics should be disclosed further with more data.

\section{Ethics Statement}

This study was approved by the Institutional Review Board of Ulsan University Hospital with a waiver of informed consent (IRB No. 2019-12-002).

\section{ORCID}

Soyeon Choi Ji Hye Kim Kyungbin Kim Misung Kim Hye Jeong Choi Young-min Kim Jae Hee Suh Min Jung Seo Hee Jeong Cha
https://orcid.org/0000-0003-1569-6592 https://orcid.org/0000-0001-7160-8601 https://orcid.org/0000-0001-5430-4235 https://orcid.org/0000-0002-7317-324X https://orcid.org/0000-0002-5124-8589 https://orcid.org/0000-0001-8266-4553 https://orcid.org/0000-0001-7032-0294 https://orcid.org/0000-0001-9037-2155 https://orcid.org/0000-0001-8744-5747

\section{Author Contributions}

Conceptualization: HJC (Hee Jeong Cha), KK. Investigation: HJC (Hee Jeong Cha), KK, SC. Supervision: HJC (Hee Jeong Cha). Visualization: HJC (Hee Jeong Cha), KK, MJS. Writing-original draft: HJC (Hee Jeong Cha), KK, SC. Writing—review \& editing: JHS, YMK, HJC (Hye Jeong Choi), HJC (Hee Jeong Cha), KK, MK, MJS, JHK, SC.

\section{Conflicts of Interest}

The authors declare that they have no potential conflicts of interest.

\section{Funding Statement}

No funding to declare.

\section{References}

1. A clinical evaluation of the International Lymphoma Study Group classification of non-Hodgkin's lymphoma. The Non-Hodgkin's Lymphoma Classification Project. Blood 1997; 89: 3909-18.

2. Schreuder MI, van den Brand M, Hebeda KM, Groenen PJ, van Krieken JH, Scheijen B. Novel developments in the pathogenesis and diagnosis of extranodal marginal zone lymphoma. J Hematop 2017; 10: 91-107.

3. Freeman C, Berg JW, Cutler SJ. Occurrence and prognosis of extranodal lymphomas. Cancer 1972; 29: 252-60.

4. El-Fattah MA. Non-Hodgkin lymphoma of the liver: a US population-based analysis. J Clin Transl Hepatol 2017; 5: 83-91.

5. Rosand CB, Valla K, Flowers CR, Koff JL. Effective management strategies for patients with marginal zone lymphoma. Future Oncol
2018; 14: 1213-22.

6. Xie H, Lv J, Ji Y, Du X, Yang X. Primary hepatic mucosa-associated lymphoid tissue lymphoma: a case report and literature review. Medicine (Baltimore) 2019; 98: e15034.

7. Nagata S, Harimoto N, Kajiyama K. Primary hepatic mucosa-associated lymphoid tissue lymphoma: a case report and literature review. Surg Case Rep 2015; 1: 87.

8. Betianu CI, Dima A, Pavaloiu G. Primary hepatic mucosa-associated lymphoid tissue lymphoma in a patient with no chronic liver disease: Case report. Radiol Case Rep 2017; 12: 715-9.

9. Bao C, Wei J, Zhao X, et al. Prognostic value of fluorine-18-fluorodeoxyglucose positron emission tomography/computed tomography in primary hepatic mucosa-associated lymphoid tissue lymphoma: a case report and review of the literature. Medicine (Baltimore) 2018; 97: e9877.

10. Obiorah IE, Johnson L, Ozdemirli M. Primary mucosa-associated lymphoid tissue lymphoma of the liver: A report of two cases and review of the literature. World J Hepatol 2017; 9: 155-60.

11. Bohlok A, De Grez T, Bouazza F, et al. Primary hepatic lymphoma mimicking a hepatocellular carcinoma in a cirrhotic patient: case report and systematic review of the literature. Case Rep Surg 2018; 2018: 9183717.

12. Khurana A, Mukherjee U, Patil N. An unusual case of hepatic lymphoma with multiple epithelial malignancies. Indian J Pathol Microbiol 2018; 61: 585-6.

13. Dong S, Chen L, Chen Y, Chen X. Primary hepatic extranodal marginal zone B-cell lymphoma of mucosa-associated lymphoid tissue type: a case report and literature review. Medicine (Baltimore) 2017; 96: e6305.

14. Li LX, Zhou ST, Ji X, et al. Misdiagnosis of primary hepatic marginal zone B cell lymphoma of mucosa-associated lymphoid tissue type, a case report. World J Surg Oncol 2016; 14: 69.

15. Haefliger S, Milowich D, Sciarra A, et al. Primary hepatic marginal B cell lymphoma of mucosa-associated lymphoid tissue (MALT) and non-alcoholic steatohepatitis (NASH): more than a coincidence? Ann Hematol 2019; 98: 1513-6.

16. Zucca E, Bertoni F, Vannata B, Cavalli F. Emerging role of infectious etiologies in the pathogenesis of marginal zone B-cell lymphomas. Clin Cancer Res 2014; 20: 5207-16.

17. Kleinstern G, Maurer MJ, Liebow M, et al. History of autoimmune conditions and lymphoma prognosis. Blood Cancer J 2018; 8: 73.

18. Baumhoer D, Tzankov A, Dirnhofer S, Tornillo L, Terracciano LM. Patterns of liver infiltration in lymphoproliferative disease. Histopathology 2008; 53: 81-90.

19. Kwon YK, Jha RC, Etesami K, Fishbein TM, Ozdemirli M, Desai CS. Pseudolymphoma (reactive lymphoid hyperplasia) of the liver: a clinical challenge. World J Hepatol 2015; 7: 2696-702.

20. Weindorf SC, Frederiksen JK. IgG4-related disease: a reminder for practicing pathologists. Arch Pathol Lab Med 2017; 141: 1476-83. 